\title{
Frequency of Hashimoto's thyroiditis in women with vitamin $D$ deficiency: A cross sectional study
}

\author{
Tayyibe Saler ${ }^{1}$, Şakir Özgür Keşkek ${ }^{2, ~ *}$, Süleyman Ahbab ${ }^{3}$, Sedat Cakir ${ }^{1}$, Gülay Ortoğlu ${ }^{2}$, \\ Mehmet Bankir², Ömer Arif Pamuk ${ }^{2}$ \\ ${ }^{1}$ Department of Internal Medicine, Umraniye Training and Research Hospital, Istanbul, Turkey \\ ${ }^{2}$ Department of Internal Medicine, Numune Training and Research Hospital Hospital, Adana, Turkey \\ ${ }^{3}$ Department of Internal Medicine, Haseki Training and Research Hospital Hospital, Istanbul, Turkey
}

\author{
Email address: \\ drkeskek@yahoo.com (Ş. Ö. Keşkek)
}

To cite this article:

Tayyibe Saler, Şakir Özgür Keşkek, Süleyman Ahbab, Sedat Cakir, Gülay Ortoğlu, Mehmet Bankir, Ömer Arif Pamuk. Frequency of Hashimoto's Thyroiditis in Women with Vitamin D Deficiency: A Cross Sectional Study. American Journal of Internal Medicine.

Vol. 2, No. 3, 2014, pp. 44-48. doi: 10.11648/j.ajim.20140203.12

\begin{abstract}
Objective: Vitamin D deficiency has been reported to be associated with different autoimmune diseases such as type 1 diabetes, rheumatoid arthritis and Crohn's disease. The aim of this study was to evaluate the association between Hashimoto's thyroiditis and vitamin D deficiency. Material and Methods: This case-control study was carried out in tertiary hospitals from 2011 to 2012. A total of 198 female subjects were included, of whom 84 and 114 participants were healthy or had vitamin D deficiency, respectively. Serum vitamin D levels, parathyroid hormone concentrations thyroid hormone levels and thyroid auto-antibodies were measured in all subjects. Results: Demographic characteristics of participants were not significantly different between the control and study groups $(p>0,05)$. Frequency of Hashimoto's thyroiditis was similar in both groups $(p=0.958)$. Thyroid auto-antibodies did not correlate with vitamin $\mathrm{D}$ levels $(\mathrm{p}>0.05)$. Conclusion: Although vitamin D deficiency is associated with some of autoimmune diseases, Hashimoto's thyroiditis was not found to be associated with vitamin D deficiency in female patients in this study.
\end{abstract}

Keywords: Vitamin D Deficiency, Hashimoto's Thyroiditis, Autoimmune Diseases

\section{Introduction}

Vitamin $D$ is a fat-soluble vitamin which is predominantly synthesized in the skin. Vitamin D and its metabolites have an important clinical role due to their interrelationship with calcium homeostasis and bone metabolism [1]. Vitamin D deficiency can be caused by low sun exposure, lack of vitamin D fortified foods and malabsorption. Impaired hydroxylation of vitamin $\mathrm{D}$ in liver or kidney can also cause deficiency [2]. Vitamin D has major effects on nearly all cells of the immune system. Antigen presenting cells, such as dendritic cells, macrophages, and $\mathrm{T}$ and $\mathrm{B}$ cells, express the vitamin $\mathrm{D}$ receptor. As an immune modulator, vitamin $\mathrm{D}$ reduces activation of the acquired immune system. Hence, vitamin D deficiency could theoretically increase the risk of autoimmune diseases such as type 1 diabetes, rheumatoid arthritis, multiple sclerosis, Graves' disease and Crohn's disease [3-6].
Hashimoto thyroiditis is an autoimmune, progressive inflammatory disorder of the thyroid gland. A dense lymphocytic infiltration of the gland is involved in the pathogenesis of Hashimoto thyroiditis. The incidence of this disease is $2 \%$ with a peak in women $30-50$ years-old [7]. Antithyroglobulin antibody (anti-Tg) and anti-thyroid peroxidase antibody (anti-TPO) are the main antibodies detected in Hashimoto thyroiditis. Genetic and environmental factors are considered the main triggers of the disease [7].

Vitamin D also inhibits generation of cytokine which plays an important role in developing autoimmune thyroiditis [8]. There are some studies which were performed to elucidate the association between vitamin D deficiency and Hashimoto's thyroiditis. However, the results of these studies are insufficient for clear information [9-12]. Frequency of vitamin D deficiency is high in women in Turkey [15]. If vitamin D deficiency is associated with Hashimoto's thyroiditis, a large number of patients have increased risk for Hashimoto's thyroiditis in 
our country. Therefore, we can prevent the developing of Hashimoto's thyroiditis in some patients. According to this link we performed the current study and we aimed to determine whether Hashimoto's thyroiditis is related to vitamin D deficiency.

\section{Materials and Methods}

This cross-sectional study was carried out in the internal medicine outpatient clinics of the Adana Numune Training and Research Hospital, and Umraniye Training and Research Hospital in Turkey, from February 2010 to March 2012. The institutional review board of the hospitals approved this experiment, and informed consent was obtained from all subjects. All procedures were followed in accordance with the ethical standards of the Responsible Committee on Human Experimentation, and with the Helsinki Declaration of 1975, as revised in 2008.

A total of 198 female subjects were included in this study. The study and control groups included 114 and 84 subjects with vitamin D deficiency or optimal vitamin D status, respectively.

Subjects with malignancies, renal diseases, liver diseases, metabolic bone diseases, primary hyperparathyroidism, diabetes, pregnancy and medications that might alter concentration of vitamin D were excluded. Subjects with past history of vitamin D deficiency and thyroid disorders were also excluded. All subjects were Muslim but they were not veiled. All of the subjects (including patients and controls) were chosen from the individuals who admitted to the internal medicine outpatient clinics of the institutes. Subjects in the control group had no any health complaints they admitted only for check-up. Additionally, they were frequency-matched to the cases according to age BMIs. Women were recruited in this study since women have more risk for vitamin D deficiency and Hashimoto's thyroiditis [7,14-16]. If vitamin D deficiency is associated with Hashimoto's thyroiditis, we should observe it in a study like a this.

A venous blood sample was collected in the morning of overnight fasting. We measured serum vitamin $\mathrm{D}$, antiTg, anti-TPO, TSH, free T4 (FT4), free T3 (FT3), PTH concentrations. Serum 25(OH)D concentration was measured for vitamin D deficiency. Other biochemical parameters included in this study were blood glucose, hepatic transaminases (AST, ALT), urea, creatinine, calcium and phosphorus. Serum 25(OH)D concentrations were measured by using commercially available enzymelinked immunosorbent kits (Minneapolis, USA). Serum $25(\mathrm{OH}) \mathrm{D}$ concentrations of $<30 \mathrm{ng} / \mathrm{ml}(75 \mathrm{nmol} / \mathrm{l})$ were defined as vitamin D deficiency and $<20 \mathrm{ng} / \mathrm{ml}(<50$ nmol/l) as severe deficiency. A value of $25(\mathrm{OH}) \mathrm{D}$ concentration greater than $30 \mathrm{ng} / \mathrm{ml}(75 \mathrm{nmol} / \mathrm{l})$ was considered as normal vitamin D level $[17,18]$. Thyroid function tests (TSH, FT3 and FT4), thyroid auto antibodies (anti-Tg, anti-TPO) and PTH were measured by electrochemiluminescent immunoassay with Abbott
Architect I 2000 SR analyser system (Illiniosis, USA). Blood glucose, AST, ALT, urea, creatinin, calcium and phosphorus were analyzed on Beckman Coulter Synchron LX 20 (Massachusetts, USA) using commercially available kits. Elevated serum levels of thyroid auto antibodies and ultrasonographic findings of thyroiditis were used for diagnosis of Hashimoto's thyroiditis.

The MedCalc 12.7 software program (MedCalc Belgium) was used for statistical analysis. Data were reported as the mean \pm SD. Kolmogorov-Smirnov test was used to show the normal distribution of quantitative measurements. Chisquare is used to test the statistical significance of differences in frequencies. T test or Mann Whitney $U$ tests were used for comparison of quantitative measurements between the two groups. Pearson correlation coefficient was used to analyse the degree of association between two variables. A log transformation was used for the variables that were not normally distributed. Multiple regression test (enter method) was used to analyse the relationship between a dependent variable and one or more independent variables (predictor variables or explanatory variables). The probability of making a Type I error (alpha, significance) is 0.05 in all tests.

\section{Results}

The mean age of study and control groups were $33.2 \pm$ $8.1,34.1 \pm 8.5$, respectively. The difference was not statistically significant $(\mathrm{p}=0.455)$. Mean BMIs were comparable in both groups $(\mathrm{p}=0.067)$. Blood glucose, AST, ALT and creatinin levels of groups were also similar $(p=0.119,0.162,0.068,0.127$, respectively) (Table 1$)$.

Table 1. Characteristics of the study and control groups.

\begin{tabular}{|c|c|c|c|c|}
\hline & $\begin{array}{l}\text { Reference } \\
\text { values }\end{array}$ & $\begin{array}{l}\text { Study group } \\
\qquad(\mathrm{N}=114)\end{array}$ & $\begin{array}{c}\text { Control } \\
\text { group } \\
(\mathrm{N}=\mathbf{8 4})\end{array}$ & $\mathbf{P}$ \\
\hline Age & & $33.2 \pm 8.1$ & $34.1 \pm 8.5$ & 0.455 \\
\hline BMI $\left(\mathrm{kg} / \mathrm{m}^{2}\right)$ & & $23.4 \pm 3.6$ & $24.3 \pm 2.8$ & 0.067 \\
\hline Glucose (mg/dL) & $74-106$ & $92.7 \pm 8.2$ & $95.0 \pm 12.7$ & 0.119 \\
\hline $\begin{array}{l}\text { Creatinine } \\
(\mathrm{mg} / \mathrm{dL})\end{array}$ & $0.5-1.1$ & $0.65 \pm 0.08$ & $0.67 \pm 0.11$ & 0.162 \\
\hline AST (IU/L) & $<40$ & $18.0 \pm 9.4$ & $18.9 \pm 7.8$ & 0.068 \\
\hline ALT (IU/L) & $<40$ & $17.4 \pm 6.3$ & $18.2 \pm 6.3$ & 0.127 \\
\hline $\mathrm{TSH}(\mu \mathrm{IU} / \mathrm{mL})$ & $0.27-4.2$ & $2.7 \pm 7.5$ & $1.9 \pm 1.0$ & 0.547 \\
\hline FT3(pg/mL) & $2.0-4.4$ & $3.0 \pm 2.4$ & $2.8 \pm 1.1$ & 0.730 \\
\hline FT4 (ng/dL) & $1.0-1.7$ & $1.08 \pm 0.14$ & $1.16 \pm 0.33$ & 0.099 \\
\hline PTH(pg/mL) & $15-65$ & $75.0 \pm 41.9$ & $62.2 \pm 32.2$ & 0.005 \\
\hline Calcium(mg/dL) & $8-10.2$ & $9.04 \pm 0.51$ & $9.29 \pm 0.44$ & 0.0004 \\
\hline $\begin{array}{c}\text { Phosphorus } \\
\text { (mg/dL) }\end{array}$ & $2-2.5$ & $3.29 \pm 0.47$ & $3.49 \pm 0.47$ & 0.004 \\
\hline $\begin{array}{c}25(\mathrm{OH}) \mathrm{D} \\
(\mathrm{ng} / \mathrm{mL})\end{array}$ & $30-80$ & $14.8 \pm 5.5$ & $38.5 \pm 8.5$ & $<0.0001$ \\
\hline $\begin{array}{c}\text { Hashimoto } \\
\text { frequency } \%(\mathrm{~N})\end{array}$ & & $15.7 \%(18)$ & $16.6 \%(14)$ & 0.958 \\
\hline
\end{tabular}

Serum TSH, FT3, FT4 concentrations of groups were not statistically different $(\mathrm{p}=0.547,0.730,0.099$, respectively). PTH concentration was high, calcium and 
phosphorus levels were low in study group. The differences were statistically significant $(p=0.005,0.0004,0.004$, respectively). Study group had a lower serum $25(\mathrm{OH}) \mathrm{D}$ concentration than control group $(14.8 \pm 5.5$ vs $38.5 \pm 8.5$, $\mathrm{p}<0.0001)$. The prevalance of Hashimoto's thyroiditis was similar in both study and control groups (15.7\% and $16.6 \%$ in subjects with and without vitamin D deficiency, respectively). The difference was not statistically significant $(\mathrm{p}=0.958$; Table 1$)$.

Correlation analyses have shown that 25(OH)D concentrations were not associated with thyroid auto antibodies ( $p>0.05$, respectively, Table 2, Figure 1,2). Multiple regression analyses (enter method) were performed with Anti Tg and Antı TPO as dependent variables and with age, BMI, $25(\mathrm{OH}) \mathrm{D}$ and TSH as independent variables. A significant correlation persisted between Anti Tg and TSH ( $p<0.001$, table 3), and between TSH and Anti TPO ( $<<0.001$; table 4).

Table 2. Correlations of 25(OH)D with thyroid auto antibodies.

\begin{tabular}{cccc}
\hline 25(OH)D & & AntiTg & AntiTPO \\
\hline Study group & $\mathrm{r}$ & 0.082 & 0.135 \\
$(\mathrm{~N}=114)$ & $\mathrm{p}$ & 0.385 & 0.149 \\
Control group & $\mathrm{r}$ & 0.123 & 0.003 \\
$(\mathrm{~N}=84)$ & $\mathrm{p}$ & 0.261 & 0.974 \\
\hline
\end{tabular}

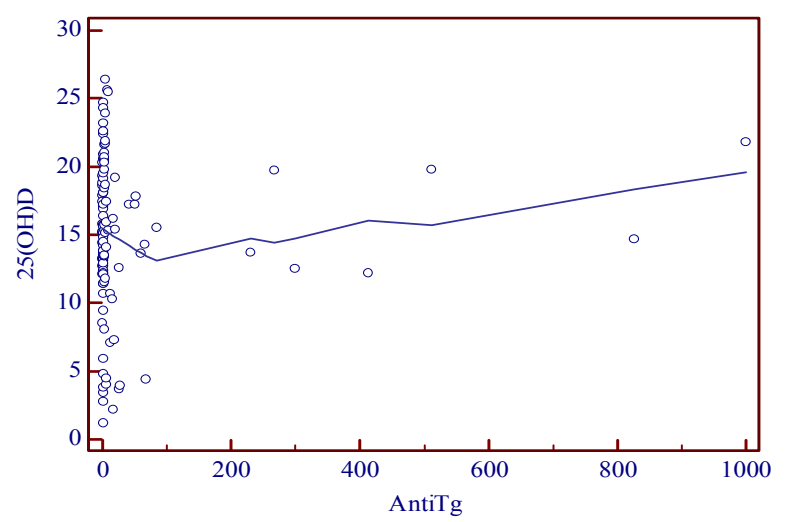

Figure 1. Scatter diagram shows that there is no any correlation between 25(OH)D and AntiTg

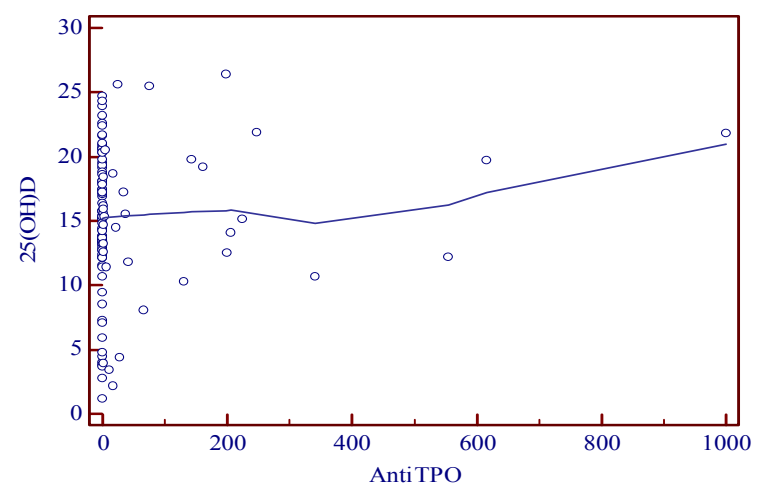

Figure 2. Scatter diagram shows that there is no any correlation between 25(OH)D and AntiTPO
Table 3. Independent predictors for AntiTg by enter regression analyses.

\begin{tabular}{ccccc}
\hline & $\begin{array}{c}\boldsymbol{\beta}- \\
\text { Coefficient }\end{array}$ & $\begin{array}{c}\text { Standard } \\
\text { error }\end{array}$ & t-value & p \\
\hline (Constant) & 13.4500 & & & \\
Age & 0.6128 & 1.1819 & 0.518 & 0.6052 \\
BMI & -1.2673 & 2.6350 & -0.481 & 0.6315 \\
$25(\mathrm{OH}) \mathrm{D}$ & -0.1133 & 1.7638 & -0.0642 & 0.9489 \\
TSH & 13.0183 & 1.2696 & 10.254 & $<0.0001$ \\
\hline
\end{tabular}

Table 4. Independent predictors for AntiTPO by enter regression analyses.

\begin{tabular}{ccccc}
\hline & $\begin{array}{c}\boldsymbol{\beta}- \\
\text { Coefficient }\end{array}$ & $\begin{array}{c}\text { Standard } \\
\text { error }\end{array}$ & t-value & p \\
\hline (Constant) & -60.7920 & & & \\
Age & 0.9001 & 1.0866 & 0.828 & 0.4093 \\
BMI & 0.6314 & 2.4224 & 0.261 & 0.7949 \\
$25(\mathrm{OH}) \mathrm{D}$ & 1.3968 & 1.6215 & 0.861 & 0.3909 \\
TSH & 12.3614 & 1.1671 & 10.591 & $<0.0001$ \\
\hline
\end{tabular}

\section{Discussion}

In this study we investigated the prevalance of Hashimoto's thyroiditis in women with or without vitamin $\mathrm{D}$ deficiency. We also investigated the association between thyroid auto antibodies and vitamin $\mathrm{D}$ levels. The main findings of our study were; the frequency of Hashimoto's thyroiditis was similar in subjects with or without vitamin $\mathrm{D}$ deficiency and the thyroid auto antibodies were not associated with serum vitamin D levels.

Patients with vitamin D deficiency are common in Turkey. Vitamin D deficiency is a widespread health problem in all regions of our country. In a study, Erkal et al. have shown that more than $78 \%$ of Turkish people have vitamin D deficiency [13]. Female subjects were prefered in this study since Hashimoto's thyroiditis and vitamin D deficiency are more common disorders in women population [7,14-16]. The ages of the subjects in our study were between the most appropriate age ranges for Hashimoto's thyroiditis because the incidence of the disease is higher in age between 30-50 years. Additonally, severe vitamin D deficiency is also common in reproductive age of women $[13,19]$.

The physiological role of thyroid hormones in the regulation of vitamin D metabolism is still unclear but it has been reported that patients with hyperthyroidism have low serum levels of vitamin D. In a study, plasma vitamin $\mathrm{D}$ was decreased in hyperthyroid mice as a consequence of decreased renal CYP27B1 mRNA expression. Additionally, antithyroid drug treatment for Graves' disease has been shown to increase vitamin D levels in another study [20,21]. In present study thyroid hormone levels of both groups were comparable and patients taking drugs that might alter concentration of vitamin $\mathrm{D}$ were excluded.

Active forms of vitamin D prevent the development of autoimmune diseases [22]. It suppresses autoimmune disease pathology by regulating differentiation and activity of CD4+ $\mathrm{T}$ cells resulting in a more balanced T1/T2 response favoring less development of self-reactive $\mathrm{T}$ cells and autoimmunity. As an immune modulator, vitamin D 
reduces activation of the acquired immune system. Therefore, vitamin D deficiency could theoretically increase the risk of autoimmune diseases such as type 1 diabetes, rheumatoid arthritis, multiple sclerosis and Graves disease [3-6]. However, the association between vitamin D deficiency and Hashimoto's thyroiditis is not clear. Kivity et al. have shown low concentrations of $25(\mathrm{OH}) \mathrm{D}$ in patients with autoimmune thyroid diseases [10] but Effraimidis et al. reported that vitamin D deficiency is not associated with early stages of thyroid autoimmunity [12]. Colak et al. reported that $94.4 \%$ of patients with Hashimoto's thyroiditis had vitamin D deficiency. In the same study severe vitamin D deficiency was found as $42.8 \%$ in females patients with Hashimoto's thyroiditis [23]. Likewise, Tamer et al. showed lower serum 25(OH)D concentrations in Hashimoto's thyroiditis compared to healthy control subjects in a younger population [11]. On the other hand, in Erkal et al. and Ergür et al. studies they have found high prevalence of vitamin D deficiency in Turkish population regardless of Hashimoto's thyroiditis $[13,19]$.

In vivo data from animals and from human vitamin D supplementation studies have shown beneficial effects of vitamin $\mathrm{D}$ on immune function, in particular in the context of autoimmunity [24]. Otherwise, Fournier et al. have shown that administration of vitamin D has little effect in reducing the severity of experimental autoimmune thyroiditis induced by immunizing CBA mice with thyroglobulin [25].

The polymorphic vitamin D binding protein greatly facilitates vitamin $\mathrm{D}$ actions, and vitamin $\mathrm{D}$ binding protein alleles differ regarding their affinity for vitamin D. In accordance with this line, Pani et al. investigated polymorphisms of the vitamin D binding protein gene for an association with thyroid autoimmunity. They have reported that vitamin D binding protein is associated with Graves' disease but not with Hashimoto's thyroiditis [26]. Similarly, Yazıcı et al. did not observed any differences between patients with Hashimoto's thyroiditis and healthy controls in terms of ApaI and BsmI polymorphisms in Turkish population [27].

Some of previous studies have investigated vitamin D levels in patients with autoimmune thyroidits. These studies concluded that low 25(OH)D concentrations was associated with autoimmune thyroiditis due to the immune system activation. However, vitamin D deficiency is more common in the populations so it can be found as a comorbidity in all diseases. For example; Erkal et al. have shown that more than $78 \%$ of Turkish people had vitamin $\mathrm{D}$ deficiency [16]. According to this line, if you measure $25(\mathrm{OH}) \mathrm{D}$ concentration in patients with coronary artery disease you may find low 25(OH)D concentrations in most of these patients. You can also find low concentrations in patients with type 2 diabetes but it is difficult to explain the association between vitamin D deficiency and these diseases. In our study, we have shown that frequency of Hashimoto's thyroiditis was comparable in both groups.
This result is supported by some results of Kivity et al. study. They reported that the prevelance of vitamin D deficiency was not different between patients with or without autoimmune thyroiditis [10].

Our study was designed as simplest compared to previous studies. We investigated the frequency of Hashimoto's thyroiditis in female subjects with or without vitamin $\mathrm{D}$ deficiency. Female gender in this study may constitute a bias, we planned this study with female gender because women have more risk for vitamin D deficiency and Hashimoto's thyroiditis so we can find more clear results. Moreover, when we looked previous studies, the majority of groups were women $[10,11,23]$.

The results can be challenging in the studies designed with common disorders if the clinical properties of the control and study group are not well-matched. Although subjects with normal $25(\mathrm{OH}) \mathrm{D}$ concentrations are rare in our region the control group in this study is a real healthy group with a normal $25(\mathrm{OH}) \mathrm{D}$ concentrations. We found the frequency of Hashimoto's thyroiditis comparable in both groups and no correlation was found between vitamin $\mathrm{D}$ and thyroid auto antibodies. Similarly, age and BMI were not correlated with auto antibodies. Not surprisingly, serum TSH concentrations were correlated with thyroid auto antibodies.

The discordence of findings between current study and other studies may depend on patient selections (gender, age, BMIs, exclusion criteria, etc), group creations (properties of groups, level of vitamin D deficiency), society differences (genetic properties, peoples).

Our study had some limitations. First, it would have been beneficial if the sample size had been larger. According to the power analyses, the power of the study is low due to the small sample size. Thus, our findings need to be replicated in larger populations. Second, we used only a single measurement of $25(\mathrm{OH}) \mathrm{D}$. On the other hand, we have strength points. First, the group selection is good in this study. All patients had vitamin D deficiency and all controls had optimal vitamin D levels. Moreover, the wide exclusion criteria is another strong point.

In conclusion, vitamin $\mathrm{D}$ deficiency is common in women in Turkey and we observed that Hashimoto's thyroiditis is not associated with vitamin D deficiency in women in our country.

\section{References}

[1] Das G, Crocombe S, McGrath M, MZ Mughal. Hypovitaminosis D among healthy adolescent girls attending an inner city school. Arch Dis Child. 2006; 91(7): 569-572.

[2] Holick MF. Vitamin D deficiency. N Engl J Med. 2007; 357(3): 266-281.

[3] Snijder M, van Dam R, Visser M, Deeg D, Seidell J, Lips P To, et al. Vitamin D and diabetes. Diabetologia 48:1247-1257. Diabetologia. 2006; 49(1): 217-218. Epub 2005 Dec 13. 
[4] Cutolo M, Otsa K, Laas K, Yprus M, Lehtme R, Secchi ME, et al. Circannual vitamin $\mathrm{D}$ serum levels and disease activity in rheumatoid arthritis: northern versus Southern Europe. Clin Exp Rheumatol. 2006; 24(6): 702-704.

[5] Munger KL, Levin LI, Hollis BW, Howard NS, Ascherio A. Serum 25-hydroxyvitamin D levels and risk of multiple sclerosis. JAMA. 2006; 296(23): 2832-2838.

[6] Yasuda T, Okamoto Y, Hamada N, Miyashita K, Takahara $\mathrm{M}$, Sakamoto F, et al. Serum vitamin D levels are decreased and associated with thyroid volume in female patients with newly onset Graves' disease. Endocrine. 2012; 42(3):739741

[7] Kirim S, Keskek SO, Köksal F, Haydardedeoglu FE, Bozkirli E, Toledano Y. Depression in patients with euthyroid chronic autoimmune thyroiditis. Endocr J. 2012; 59(8): 705-708.

[8] Deluca HF, Cantorna MT. Vitamin D: its role and uses in immunology. FASEB J. 2001; 15(14): 2579-2585.

[9] Goswami R, Marwaha RK, Gupta N, Tandon N, Sreenivas V, Tomar N, Ray Det al. Prevalence of vitamin D deficiency and its relationship with thyroid autoimmunity in Asian Indians: a community-based survey. Br J Nutr. 2009; 102(3): 382- 386 .

[10] Kivity S, Agmon-Levin N, Zisappl M, Shapira Y, Nagy EV, Dankó K, et al. Vitamin D and autoimmune thyroid diseases. CeIl Mol Immunol. 2011; 8(3): 241- 247.

[11] Tamer G, Arik S, Tamer I, Coksert D. Relative vitamin D insufficiency in Hashimoto's thyroiditis. Thyroid. 2011; 21(8): $891-896$.

[12] Effraimidis G, Badenhoop K, Tijssen JGP, Wiersinga WM. Vitamin D deficiency is not associated with early stages of thyroid autoimmunity. Eur J Endocrinol. 2012; 167(1): 43-48.

[13] Erkal MZ, Wilde J, Bilgin Y, Akinci A, Demir E, Bödeker $\mathrm{RH}$, et al. High prevalence of vitamin D deficiency, secondary hyperparathyroidism and generalized bone pain in Turkish immigrants in Germany: identification of risk factors. Osteoporos Int. 2006; 17(8): 1133-1140.

[14] Alagöl F, Shihadeh Y, Boztepe H, Tanakol R, Yarman S, Azizlerli $\mathrm{H}$, et al. Sunlight exposure and vitamin D deficiency in Turkish women. J Endocrinol Invest. 2000; 23(3):173-177.

[15] Gudovan E, Diaconescu C, Oros S, Neamtu C. Autoimmune thyroiditis associated with polycystic ovary syndromecomments about 25 cases. Acta Endocrinol (Buc). 2008; 9(2): 173-180.

[16] Mocanu V. Vitamin D deficiency and metabolic syndrome among nursing home residents. Acta Endocrinol (Buc). 2013; 9(1): 53-62.

[17] Bringhurst FR, Demay MB, Krane SM, Kronenberg HM. Bone and mineral metabolism in health and disease. In: Longo DL, et al (eds). Harrison's principles of internal medicine 18th ed. New York: Mc Graw Hill, 2012: 30823093.

[18] Fitzgerald PA. Endocrine Disorders. In: Papadakis MA, McPhee SJ (eds). Current Medical Diagnosis and Treatment 52nd ed. New York: Mc Graw Hill, 2013: 1149.

[19] Ergür AT, Berberoğlu M, Atasay B, Şıklar Z, Bilir P, Arsan $S$, et al. Vitamin d deficiency in Turkish mothers and their neonates and in women of reproductive age. J Clin Res Pediatr Endocrinol. 2009; 1(6): 266-269.

[20] Kozai M, Yamamoto H, Ishiguro M, Harada N, Masuda M, Kagawa $\mathrm{T}$, et al. Thyroid hormones decrease plasma $1 \alpha, 25$ dihydroxyvitamin $\mathrm{D}$ levels through transcriptional repression of the renal 25-hydroxyvitamin D3 1 $\alpha$ hydroxylase gene (CYP27B1). Endocrinology. 2013; 154(2): 609-622.

[21] MacFarlane IA, Mawer EB, Berry J, Hann J. Vitamin D metabolism in hyperthyroidism. Clin Endocrinol (Oxf).1982; 17(1): 51-59.

[22] Bischoff-Ferrari HA. Optimal serum 25-hydroxyvitamin D levels for multiple health outcomes. Adv Exp Med Biol. 2008; 624: 55-71.

[23] Colak B N, Karbek B, Ucan B, Sahin M, Cakal E, Ozbek M, et al. The association between severity of vitamin $d$ deficiency and Hashimoto's thyroiditis. Endocr Pract. 2013; 19(3): 479-484.

[24] Prietl B, Treiber G, Pieber TR, Amrein K. Vitamin D and immune function. Nutrients. 2013; 5(7): 2502-2521.

[25] Fournier C, Gepner P, Sadouk M, Charreire J. In vivo beneficial effects of cyclosporin $A$ and 1,25dihydroxyvitamin D3 on the induction of experimental autoimmune thyroiditis. Clin Immunol Immunopathol. 1990; 54(1): 53-63.

[26] Pani MA, Regulla K, Segni M, Hofmann S, Hüfner M, Pasquino AM, et al. A polymorphism within the vitamin Dbinding protein gene is associated with Graves' disease but not with Hashimoto's thyroiditis. J Clin Endocrinol Metab. 2002 87(6): 2564-2567.

[27] Yazici D, Yavuz D, Tarcin O, Sancak S, Deyneli O, Akalin S. Vitamin D receptor gene ApaI, TaqI, FokI and BsmI polymorphisms in a group of Turkish patients with Hashimoto's thyroiditis. Minerva Endocrinol. 2013; 38(2): 195-201. 